\title{
BMJ Open Postnatal epigenetic modification of glucocorticoid receptor gene in preterm infants: a prospective cohort study
}

\author{
Masato Kantake, ${ }^{1}$ Hiroshi Yoshitake, ${ }^{2}$ Hitoshi Ishikawa, ${ }^{3}$ Yoshihiko Araki, ${ }^{2}$ \\ Toshiaki Shimizu ${ }^{4}$
}

To cite: Kantake $\mathrm{M}$, Yoshitake $\mathrm{H}$, Ishikawa $\mathrm{H}$, et al. Postnatal epigenetic modification of glucocorticoid receptor gene in preterm infants: a prospective cohort study. BMJ Open 2014;4: e005318. doi:10.1136/ bmjopen-2014-005318

- Prepublication history and additional material is available. To view please visit the journal (http://dx.doi.org/ 10.1136/bmjopen-2014005318).

Received 22 March 2014 Revised 5 June 2014 Accepted 25 June 2014

CrossMark

For numbered affiliations see end of article.

Correspondence to Dr Masato Kantake; kantake@juntendo-urayasu.jp

\section{ABSTRACT}

Objective: To examine the environmental effects on cytosine methylation of preterm infant's DNA, because early life experiences are considered to influence the physiological and mental health of an individual through epigenetic modification of DNA.

Design: A prospective cohort study, comparison of epigenetic differences in the glucocorticoid receptor (GR) gene between healthy term and preterm infants.

Setting: Neonatal Intensive Care Unit in a Japanese University Hospital.

Participants: A cohort of 40 (20 term and 20 preterm) infants was recruited on the day of birth, and peripheral blood was obtained from each infant at birth and on postnatal day 4 .

Main outcome measures: The methylation rates in the $1-\mathrm{F}$ promoter region of the GR gene using the Mquant method.

Results: The methylation rate increased significantly between postnatal days 0 and 4 in preterm infants but remained stable in term infants. Thus, the methylation rate was significantly higher in preterm than in term infants at postnatal day 4 . Several perinatal parameters were significantly correlated with this change in the methylation rate. Logistic regression analysis revealed that methylation rates at postnatal day 4 predicted the occurrence of later complications that required glucocorticoid administration during the neonatal period. No gene polymorphism was detected within the GR promoter region analysed.

Conclusions: Although further large-scale studies are needed to detect the environmental factors that explain the difference in epigenetic modification among infants after birth, our data show that the postnatal environment influences epigenetic programming of $G R$ expression through methylation of the GR gene promoter in premature infants, which may result in relative glucocorticoid insufficiency during the postnatal period.

\section{INTRODUCTION}

Many human and animal studies have documented the impact of early life experiences on the neurobiological regulation of stress

\section{Strengths and limitations of this study}

- Postnatal environment resets the epigenetic modification of GR gene promoter during four days after birth in preterm infants.

- This epigenetic modification may result in relative glucocorticoid insufficiency during the postnatal period.

- Large-scale studies will be expected to clarify the environmental factors that explain the difference in epigenetic modification among infants after birth.

responsiveness, mood and anxiety disorders. ${ }^{1-4}$ Maternal care, familial functioning and childhood adversity all contribute to neurobiological regulation through epigenetic modification of DNA, which is thought to be highly stable across a lifespan. ${ }^{5-7}$ Hippocampal glucocorticoid receptors (GRs) play a central role in modulating hypothalamus pituitary adrenal (HPA) axis activity. ${ }^{8-10}$ Exon 1-F of the human GR gene is similar to rat exons $1-7$, which is related to a maternal effect on cytosine methylation and expression. ${ }^{11}$ Several human studies have reported a relationship between early life experience and epigenetic modification of the GR 1-F promoter region. ${ }^{11-16}$ These studies have shown that adverse early life experiences, such as maternal depression in the third trimester, disruption of adequate nurturing and history of childhood abuse, are associated with increased methylation of the GR promoter in leucocytes, ${ }^{12-15}$ the hippocampus ${ }^{11}$ and the placenta. ${ }^{16}$

The stress of birth exceeds that of any other critical life event. Indeed, exposure to preterm labour and postnatal environmental stress, including the requisite acute care and prolonged physical separation under neonatal intensive care, may be the most adverse environments during early life. Preterm birth is associated with significant long-term neurodevelopmental impairments. ${ }^{17-21}$ 
Increased methylation of the GR promoter in leucocytes may lead to down regulation of cell surface GR expression that, in turn, results in GR resistance (GCR). GCR refers to a decrease in the sensitivity of immune cells to glucocorticoid hormones that normally terminate the inflammatory response. ${ }^{22-24}$ Evidence for GCR in response to prolonged stress has been found in humans, such as families of patients with cancer or those reporting high levels of loneliness. ${ }^{25-27}$ On the other hand, relative adrenal insufficiency occurs when the HPA axis produces insufficient cortisol relative to the degree of illness or stress. Several studies have reported a relative adrenal insufficiency in infants who develop chronic lung disease (CLD) ${ }^{28} 29$ and cardiovascular instability ${ }^{30-32}$ including late onset circulatory collapse (LCC). LCG is thought to be caused by late-onset adrenal insufficiency. An endocrinological study noted that even though relative glucocorticoid insufficiency in preterm infants is an underlying factor contributing to LCC, cortisol concentrations did not differ between the LCC and control infant groups. ${ }^{33} 34$ Therefore, another factor(s), including GCR, may be the cause of LCC.

To test the hypothesis that an increase in cytosine methylation within the GR promoter during the perinatal period in preterm infants causes physiological impairment in later life, we first compared epigenetic differences in the leucocyte GR promoter 1-F region (containing $33 \mathrm{CpG}$ sites ranging from $-3479 \mathrm{bp}$ to $-3259 \mathrm{bp}$ upstream of the ATG start site) between healthy term and preterm infants on day 0 of birth and postnatal day 4. Furthermore, we examined the relationship between the postnatal change in the methylation rates and perinatal parameters and whether the methylation status on postnatal day 4 caused complications in the neonatal period, such as CLD and LCC, which are thought to be caused by relative adrenal insufficiency.

\section{METHODS}

\section{Prospective cohort study}

We recruited a cohort of 40 consecutive infants (20 term and 20 preterm) on the day of birth between April and October 2012 at our hospital. Eligible term infants were born within 37-41 weeks of gestation and received routine postnatal care as follows: day 0, skin to skin contact for $30 \mathrm{~min}$ from $30 \mathrm{~min}$ after birth; day 1 , nursing four times (vaginal delivery (VD)) or one time (Caesarean section $(\mathrm{C} / \mathrm{S}))$; day 2, rooming with the baby (VD), nursing one time $(\mathrm{C} / \mathrm{S})$; day 3 , rooming with the baby $(\mathrm{VD})$, nursing six times $(\mathrm{C} / \mathrm{S})$; day 4 , discharge $(\mathrm{VD})$, rooming with the baby $(\mathrm{C} / \mathrm{S})$; day 5 , rooming with the baby $(\mathrm{C} / \mathrm{S})$; day 6 , discharge $(\mathrm{C} / \mathrm{S})$.

An infant was defined as preterm if born before week 37 of gestation and admitted to the neonatal intensive care unit (NICU) as premature. Patients born before 37 weeks of gestation and who did not require admission to the NICU were excluded. All preterm infants in our study were exposed to maternal separation for at least
4 days after birth. Small for gestational age (SGA) was defined as weight below the 10th centile for gestational age. The criteria for CLD were the need for additional oxygen after 28 days of age. ${ }^{35}$ The criteria for LCC were (1) sudden systemic hypotension (mean arterial pressure $<35 \mathrm{~mm} \mathrm{Hg}$ sustained for at least $3 \mathrm{~h}$ ); (2) oliguria $(<1 \mathrm{~mL} / \mathrm{kg} / \mathrm{h}$ during an $8 \mathrm{~h}$ interval); (3) electrolyte abnormality (hyponatremia $<130 \mathrm{mEq} / \mathrm{L}$, hyperkalemia $>5.5 \mathrm{mEq} / \mathrm{L}$ ) and (4) excess body weight gain per day $(15 \mathrm{~g} / \mathrm{kg}$ per day or $1.5 \%$ per day). When more than two of these symptoms were detected seven or more days postnatally, and after all other common conditions causing systemic hypotension and oliguria, such as hypovolemia, dehydration, symptomatic patent ductus arteriosus and sepsis were ruled out, corticosteroid treatment was started. LCC was diagnosed once the infant responded to corticosteroid therapy. Daily changes in body weight, mean arterial pressure, serum sodium and potassium concentrations and urine output before and at symptom onset were also assessed to help the attending physician make the diagnosis of LCG. ${ }^{34}$

\section{Methylation analysis}

Peripheral blood was obtained from the umbilical cord (day 0 ) or peripheral vein (day 4) from each infant and stored at $-80^{\circ} \mathrm{C}$ until use. Blood was sampled at day 4 in term infants in conjunction with a metabolic screening test recommended for all infants born in Japan. According to the manufacturer's instruction, genomic DNA was extracted from $2 \mu \mathrm{L}$ of frozen peripheral blood and bisulfite treated using an EZ DNA Methylation Direct Kit (Zymo Research Corp., Irvine, California, USA); $1 \mu \mathrm{L}$ of the resulting $10 \mu \mathrm{L}$ bisulfite-treated genomic DNA solution was then subjected to PCR to amplify the GR promoter 1-F region, as described previously. ${ }^{11}$ The Mquant method described by Leakey $e t a l^{36}$ was used to calculate the GR promoter methylation rate (see online supplementary methods).

\section{Statistical analysis}

We performed Wilcoxon's signed-rank test to evaluate the longitudinal difference between days 0 and 4 after birth in preterm and term group infants. We performed the Mann-Whitney $\mathrm{U}$ test to compare the methylation rates in the preterm and term groups at each CpG site. We performed the $\chi^{2}$ tests (for gestational age, birth weight and Apgar score (at 1 and 5 min)), and Mann-Whitney U tests (for intrauterine growth retardation, $\mathrm{C} / \mathrm{S}$ delivery, respiratory distress, mechanical ventilation, intracranial haemorrhage, bacterial infection and antenatal steroid administration) to compare the characteristics of each group of infants as shown in table 1. Stepwise multiple regression analysis was performed to investigate the relationships of the increased ratio of methylation rates as a dependent variable, with the perinatal parameters in preterm infants as independent variables. To perform this stepwise multiple regression analysis, several nominal variables were 
Table1 Participant characteristics

\begin{tabular}{|c|c|c|c|}
\hline & Preterm $(n=19)$ & Term $(n=20)$ & $\begin{array}{l}\text { p Value } \\
\text { (preterm vs term) }\end{array}$ \\
\hline Gestational age (weeks) (mean \pm SD) & $30.8 \pm 3.2$ & $39.8 \pm 1.3$ & $<0.001$ \\
\hline Birth weight $(g)($ mean $\pm S D)$ & $1431 \pm 605$ & $3076 \pm 271$ & $<0.001$ \\
\hline Intrauterine growth retardation (n) & 7 & 1 & 0.014 \\
\hline Caesarean section delivery (n) & 15 & 3 & $<0.001$ \\
\hline Apgar score at 1 min (mean $\pm S D)$ & $6.3 \pm 2.6$ & $9 \pm 0$ & $<0.001$ \\
\hline Apgar score at $5 \min (\operatorname{mean} \pm S D)$ & $8.4 \pm 1.2$ & $10 \pm 0$ & $<0.001$ \\
\hline Respiratory distress (n) & 10 & 0 & $<0.001$ \\
\hline Mechanical ventilation $(n)$ & 10 & 0 & $<0.001$ \\
\hline Intracranial haemorrhage (n) & 0 & 0 & 1 \\
\hline Bacterial infection (n) & 0 & 0 & 1 \\
\hline Antenatal steroid administration $(\mathrm{n})$ & 10 & 0 & $<0.001$ \\
\hline
\end{tabular}

converted to categorical variables by grouping values into two categories. The adjusted coefficient of determination $\left(\mathrm{R}^{2}\right)$ is the fraction of information of the dependent variable that is explained by the independent variables. Logistic regression analysis was performed to investigate the relationships between the methylation rate at 4 days as a dependent variable with later complications in the neonatal period as independent variables. The goodness of fit of the logistic regression models was assessed using Pearson residuals. The pseudo- $\mathrm{R}^{2}$ is the fraction of information of the dependent variable that is explained by the independent variables. ${ }^{37}$ We used the likelihood ratio test to test the hypothesis regarding which dependent variable is significantly better among the four CpGs. A p value $<0.05$ (two-tailed) was considered significant. All statistical analyses were carried out using the StatView R 5.0J for Windows (SAS Institute, Cary, North Carolina, USA) software package.

\section{RESULTS}

\section{Participant characteristics}

Thirty-nine of the 40 participants completed the analysis. Bisulfite-treated genomic DNA from one infant from the preterm group could not be amplified by PCR for unknown reasons. The characteristics of the infants are shown in table 1 . Ten of 19 preterm infants received antenatal steroids. The preterm infants had higher rates of intrauterine growth retardation than that of infants delivered by $\mathrm{C} / \mathrm{S}$. They had lower Apgar scores at 1 and 5 min compared with those of term infants. Preterm infants displayed higher rates of respiratory distress and required mechanical ventilation more frequently during the postnatal period than did term infants. None of the infants experienced a bacterial infection or intracranial haemorrhage through postnatal day 4. No gene polymorphism was detected within the GR promoter region analysed.

\section{Longitudinal changes in methylation status}

We examined $33 \mathrm{CpG}$ sites in the GR 1-F promoter. In preterm infants, methylation rates significantly increased between birth and postnatal day 4 at 11 CpG sites (1, $\mathrm{p}=0.022 ; 2, \mathrm{p}=0.044 ; 8, \mathrm{p}=0.00029 ; 9, \mathrm{p}=0.049 ; 10$, $\mathrm{p}=0.044 ; 14, \mathrm{p}=0.0013 ; 16, \mathrm{p}=0.0022 ; 25, \mathrm{p}=0.036 ; 26$, $\mathrm{p}=0.049 ; 28, \mathrm{p}=0.00097 ; 29, \mathrm{p}=0.016)$ and significantly decreased at one $\mathrm{CpG}$ site $(4, \mathrm{p}=0.030)$. In contrast, methylation rates between birth and postnatal day 4 were stable in term infants (figure 1).

\section{Cross-sectional differences in methylation status}

Methylation rates in preterm infants at birth were lower at three CpG sites $(1 ; \mathrm{p}=0.033,5 ; \mathrm{p}=0.0024,8 ; \mathrm{p}=0.0001)$ and higher at one site $(4 ; \mathrm{p}=0.040)$ compared with those in term infants. Methylation rates on postnatal day 4 were significantly higher in preterm infants compared with term infants at seven CpG sites $(15, \mathrm{p}=0.00061 ; 16$, $\mathrm{p}=0.0083 ; 21, \mathrm{p}=0.043 ; 25, \mathrm{p}=0.0098 ; 26, \mathrm{p}=0.0050 ; 27$, $\mathrm{p}=0.00040 ; 28, \mathrm{p}=0.038)$. Methylation rates in preterm infants were not lower than those of term infants at any CpG site (figure 2).

Figure 3 shows the changes in methylation status in each group between birth and postnatal day 4 at $\mathrm{CpG}$ sites 16, 25, 26 and 28. Methylation rates at these sites significantly increased only in preterm infants, resulting in a significantly higher methylation rate in preterm than in term infants on postnatal day 4 .

\section{Relationship between methylation rates at birth and perinatal parameters}

We analysed the relationship between the methylation rates at birth at $\mathrm{CpG}$ sites 1, 4, 5 and 8 and prenatal parameters such as gestational age, birth weight, SGA, antenatal steroid administration and mode of delivery. We found no significant correlation among them.

\section{Relationship between the increase in the methylation} rate ratio and perinatal parameters

To examine the relationship between the increased methylation rate ratio and perinatal parameters, we chose 12 CpG sites $(1,2,4,8,9,10,14,16,25,26,28$, and 29) in which the methylation rates were significantly increased (with the exception of CpG4), and calculated the ratio as 
the methylation rate at day 4 divided by that at day 0 . Then we investigated the relationship between the change in ratio at each CpG site and the perinatal parameters of gestational age, birth weight, Apgar score, mode of delivery, SGA, respiratory distress syndrome (RDS), mechanical ventilation, antenatal steroid administration and admission to the NICU. We found associations between these parameters and an increase in the methylation rate ratio at CpG4, CpG8, CpG10, CpG25 and CpG29. The change in methylation ratio at each $\mathrm{CpG}$ site was associated with following perinatal parameters in the parenthesis: CpG4 (gestational age and Apgar score at $1 \mathrm{~min}$ (regression coefficient $=0.029$ and -0.085 , respectively; overall $\mathrm{p}$ value $=0.004$; adjusted- $\left.\mathrm{R}^{2}=0.223\right)$ ); CpG8 (SGA, C/S, Apgar score at $5 \mathrm{~min}$, and NICU admission (regression coefficient $=0.43,-0.31,0.16$, and 0.79 , respectively; overall $\mathrm{p}$ value $<0.0001$; adjusted- $\mathrm{R}^{2}=0.573$ ) ); CpG10 (NICU admission (regression coefficient $=0.29$; overall $\mathrm{p}$ value $=0.037$; adjusted-R $\left.{ }^{2}=0.089\right)$ ); CpG25 (SGA (regression coefficient $=0.86$, overall $\mathrm{p}$ value $=0.009$, adjusted $\left.-\mathrm{R}^{2}=0.15\right)$ ) and CpG29 (SGA (regression coefficient $=0.096$, overall $\mathrm{p}$ value $=0.039$, adjusted- $\left.\mathrm{R}^{2}=0.086\right)$ ), respectively.
Relationship between methylation rate at postnatal day 4 and complications during the neonatal period

We chose four CpG sites (16, 25, 26 and 28) shown in figure 3 to investigate the relationship between methylation status on postnatal day 4 and complications during the perinatal period. Then, we analysed the relationship between the methylation rate at these $\mathrm{CpG}$ sites on postnatal day 4 and subsequent complications. There were four preterm infants who had some complications and needed glucocorticoid administration during the neonatal period. (CLD; n=3, LCC; n=3) Except for these four cases, no infant received glucocorticoid therapy postnatally.

The logistic regression models were statistically fit (Pearson residuals, $\chi^{2}=19.284, p=0.9799$, pseudo- $\mathrm{R}^{2}=0.429$ ). CpG16 had a significantly better explanatory factor among four CpGs (likelihood ratio test $\chi^{2}=3.889, \mathrm{p}=0.0486$ ).

\section{DISCUSSION}

Our study is the first longitudinal analysis of GR promoter methylation in humans during the perinatal period, the stage that is thought to be the most

\section{Mean \pm SEM Longitudinal analysis $\quad \begin{aligned} & \text { day } 0 \quad \star_{\text {day } 4} \quad 0.05 \\ & \star\end{aligned}$}
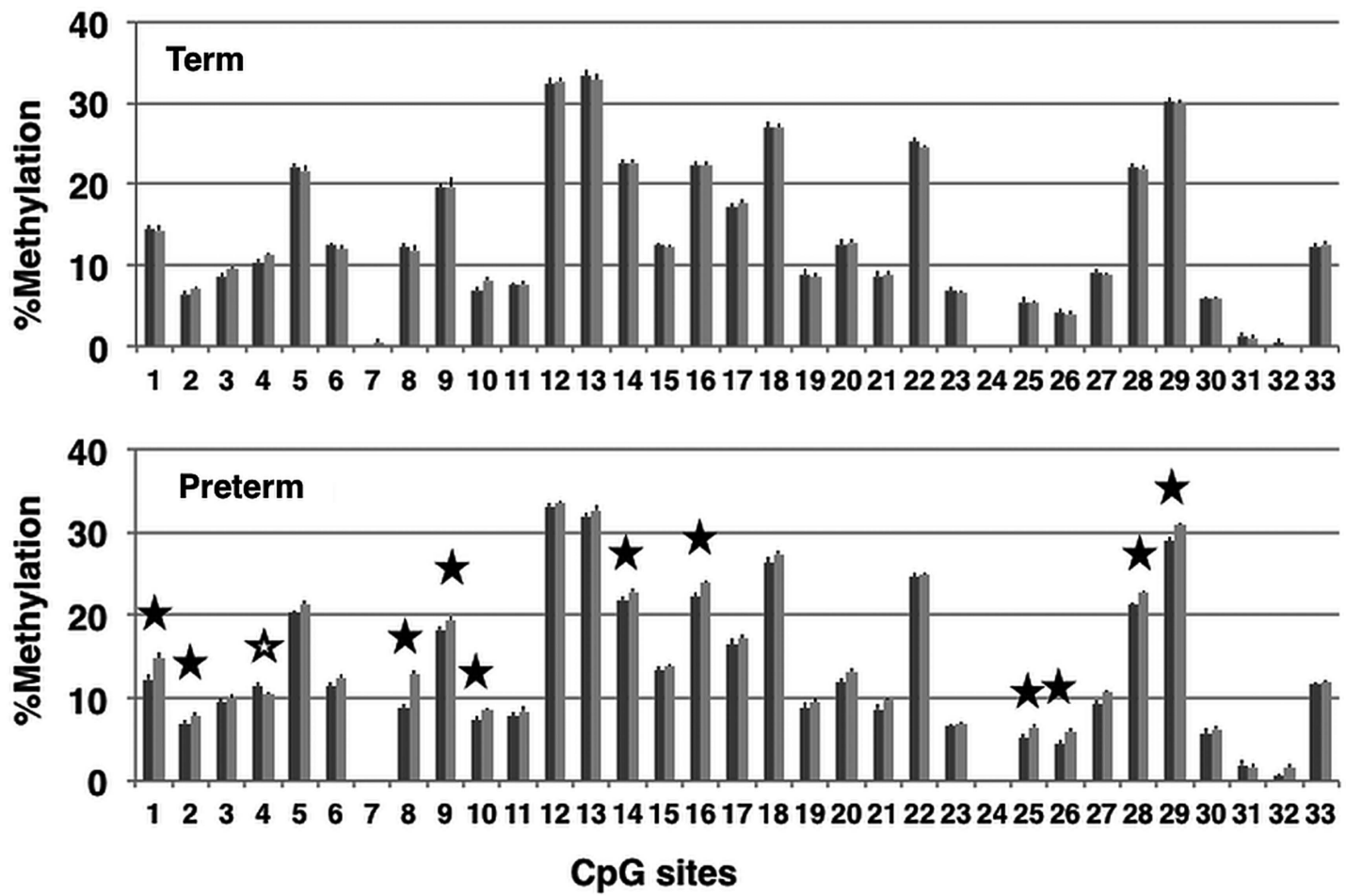

Figure 1 Longitudinal analysis of the methylation rate of the glucocorticoid receptor (GR) gene promoter in the leucocyte calculated using the Mquant method. The percentage of methylation at each $\mathrm{CpG}$ site (mean \pm SEM) in the GR promoter isolated in peripheral blood collected from term and preterm infants at birth (dark grey bar) and postnatal day 4 (light grey bar), respectively. Wilcoxon's signed-rank test was performed to compare the methylation rate on day 0 and day 4 at each $\mathrm{CpG}$ site. A p value $<0.05$ (two tailed) was considered statistically significant. Closed star symbol, significant increase in methylation rate; Open star symbol, significant decrease in methylation rate. No significant changes in methylation rate between postnatal days 0 and 4 were observed in term infants. 


\section{Mean \pm SEM Cross sectional analysis $\quad \begin{aligned} & \text { Term } \\ & \text { Preterm }\end{aligned} \stackrel{\hbar}{\hbar} \boldsymbol{p}<0.05$}
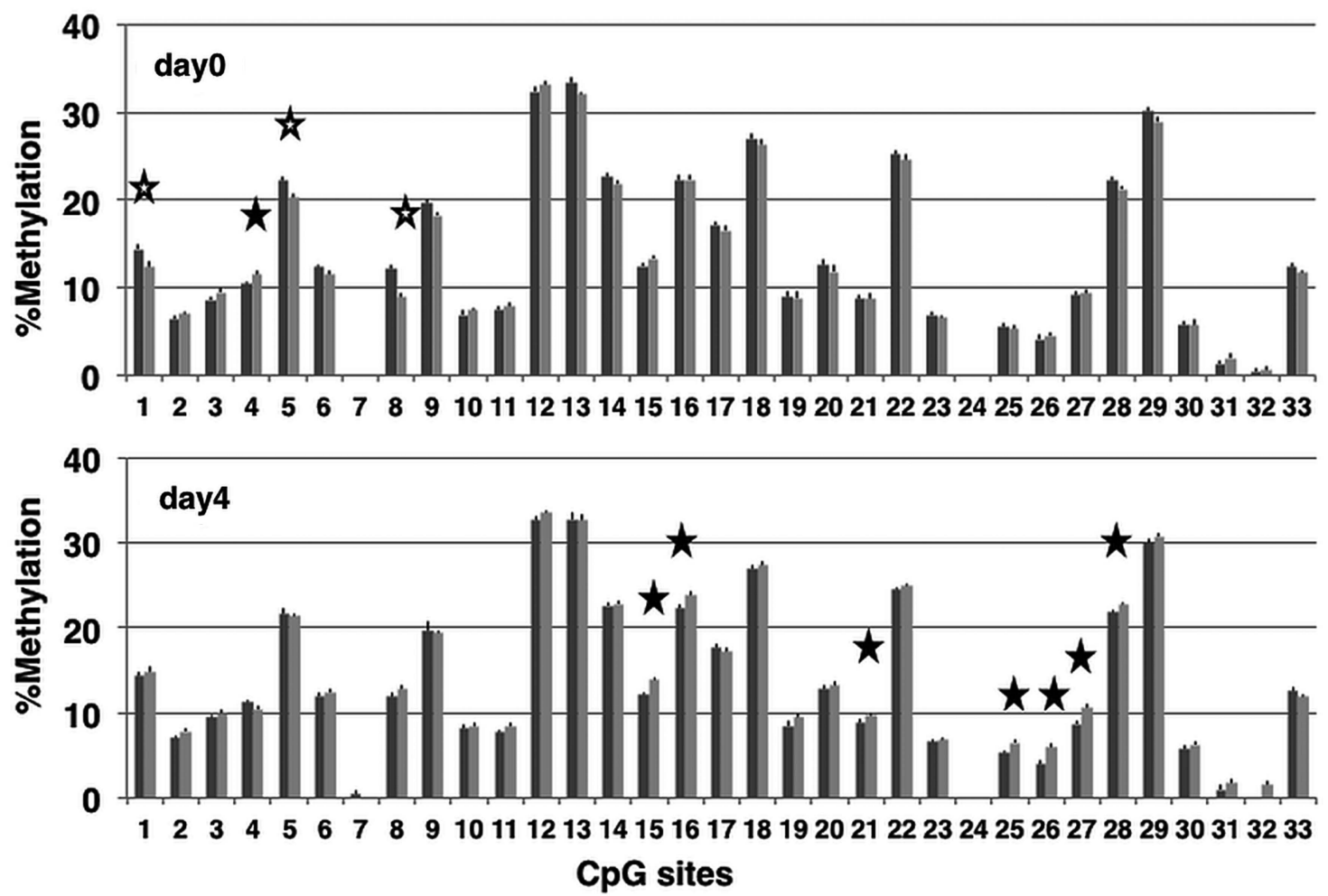

Figure 2 Cross-sectional analysis of the methylation rates of the glucocorticoid receptor (GR) gene promoter in leucocytes determined using the Mquant method. Percentage of methylation at each CpG site (mean \pm SEM) in the GR promoter isolated from peripheral blood collected at birth and on postnatal day 4 in term (dark grey bar) and preterm (light grey bar) infants, respectively. Mann-Whitney $U$ tests were performed to compare the methylation rates in preterm and term infants at each CpG site. A p value $<0.05$ (two tailed) was considered statistically significant. Closed star symbol, methylation rate significantly higher in preterm compared with term infants; Open star symbol, methylation rate significantly lower in preterm compared with term infants.

susceptible to epigenetic regulation. The present study demonstrated that postnatal exposure to an adverse environment in preterm infants influences epigenetic programming of the glucocorticoid response via GR promoter methylation during the neonatal period.

We found that perinatal parameters such as gestational age, intrauterine growth, Apgar score and mode of delivery were predictors for changes in methylation rates at CpG sites in the GR promoter as well as NICU admission.

It should be noted that gestational age was positively associated with an increase in the methylation ratio at CpG4. Exposure to preterm labour may be an adverse environment in early life. Therefore, the methylation rate ratio at $\mathrm{CpG} 4$ should be negatively associated with gestational age. CpG4 was the only site at which the methylation rates in preterm infants were significantly higher than those in term infants at birth. Moreover, CpG4 was the only site at which the methylation rate was lower on postnatal day 4 than on day 0 . Taken together, the change in methylation at CpG4 seemed to be regulated inversely, compared with other CpG sites. The mechanisms underlying DNA methylation and demethylation probably develop due to unfavourable experiences during early life; however, recent studies that have investigated other transcripts of the GR gene have proposed a more complex child maltreatmentinduced DNA methylation model than previously described for exon $1-\mathrm{F}^{38}$ In the present study, CpG4 may be a transcriptionally silent methylation site that mediated aberrant epigenetic regulation, as proposed by Lutz et $a l^{38}$ Low Apgar score, which is thought to be an unfavourable experience during the perinatal period, is positively associated with the CpG4 methylation ratio increase and negatively associated with that of CpG8. Thus, low Apgar score may have a negative effect on methylation in most CpG sites in the GR 1-F promoter. One possible explanation is that low Apgar score indicates an adverse condition of cardiopulmonary function, which, in turn, inactivates the enzymatic cascade for DNA methylation. Stable oxygen and energy supplements may be necessary to open the window for epigenetic programming by DNA methylation. C/S delivery was negatively associated with an increase in the methylation ratio at CpG8. This obstetrical intervention may partially reduce stress-induced epigenetic programming of the GR promoter. SGA was positively associated with an 

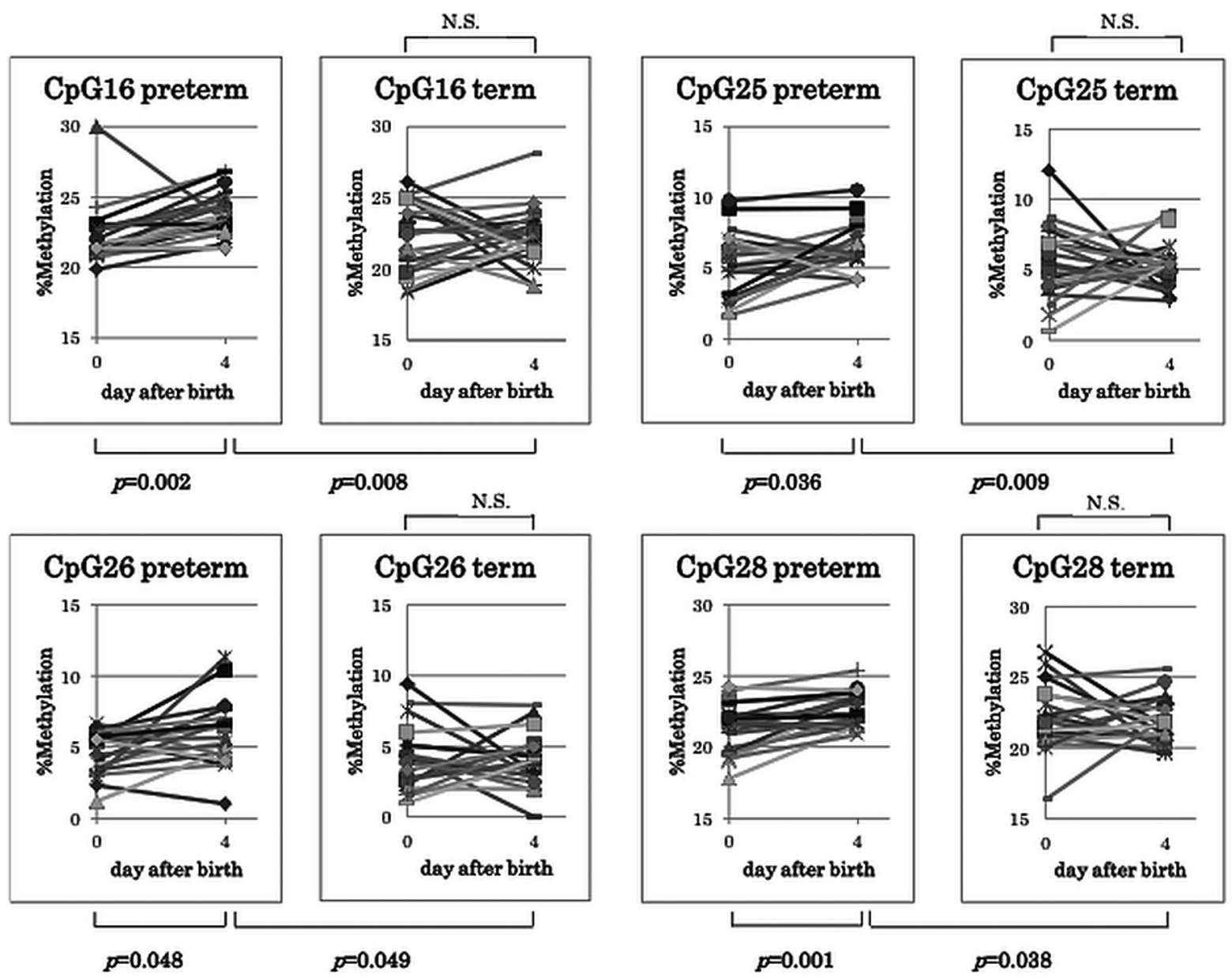

Figure 3 Change in methylation status between birth and postnatal day 4 at CpG sites 16, 25, 26 and 28. Methylation rates at these sites were significantly greater in preterm than in term infants resulting in a significantly higher methylation rate ratio in the preterm infants on postnatal day 4 . The day 0 and day 4 methylation rate ratios were compared using Wilcoxon's signed-rank test. The Mann-Whitney $U$ test was performed to compare the methylation rates in preterm infants with those in term infants. ns, not significant.

increase in methylation rate ratio at CpG8, 25 and 29. The intrauterine environment, like the postnatal environment, can affect fetal epigenetic modification of DNA. SGA infants have been thought to demonstrate epigenomic dysregulation, which mediates the long-term consequences of intrauterine growth restriction at birth. $^{39} 40$ The present study shows that, in the GR gene, SGA might influence the infant's susceptibility to the postnatal environment rather than epigenomic dysregulation at birth. As we expected, NICU admission followed by maternal separation was positively associated with an increase in the methylation rate ratio at CpG8 and 10. Taken together, we could approximately estimate the relationship between perinatal parameters and changes in methylation rates at CpG sites in the GR promoter. Further precise analysis should give insights into the host-environment interaction.

Four preterm infants needed glucocorticoid administration during the postnatal period due to CLD or LCC. The logistic regression models were statistically fit to predict the development of these complications (CLD and LCC), which were thought to be partly related to relative adrenal insufficiency. CpG16 had a significantly better explanatory factor among the four CpGs in which methylation rates increased significantly only in preterm infants resulting in a significantly higher methylation rate in preterm than in term infants on postnatal day 4. CpG16 is a binding site for nerve growth factor inducible protein A (NGFI-A), which has emerged as a central regulator of early inflammatory and immune processes and potentiates GR 1-F promoter activity. ${ }^{11} 41-43$

Taken together, our results suggest that the high methylation rate observed in leucocyte GR promoters may result in GR unresponsiveness to early inflammatory stimuli by NGFI-A, followed by GCR and/or a failure to downregulate inflammatory responses by glucocorticoids. ${ }^{44}$

One limitation of our study was the small sample size. Further studies with larger sample sizes that include patients with chronic inflammation are needed.

\section{CONCLUSIONS}

We found marked changes in DNA methylation induced by the postnatal environment during the 4 days 
immediately after birth. Moreover, the methylation status at postnatal day 4 may predict the development of complications during the neonatal period, which is thought to be induced by relative glucocorticoid insufficiency in preterm infants.

\section{Author affiliations}

${ }^{1}$ Perinatal Medical Center, Juntendo University Urayasu Hospital, Urayasu, Chiba, Japan

${ }^{2}$ Institute for Environmental \& Gender-specific Medicine, Juntendo University Graduate School of Medicine, Urayasu, Chiba, Japan

${ }^{3}$ Department of Health Information Management, Yamagata Saisei Hospital, Yamagata, Yamagata, Japan

${ }^{4}$ Department of Pediatrics, Juntendo University Graduate School of Medicine, Bunkyo, Tokyo, Japan

Acknowledgements The authors express our appreciation to Dr Satoru Yamaguchi for sample collection. We are deeply indebted to Drs Kaoru Obinata and Kenji Takamori for their encouragement throughout the course of this study.

Contributors MK and TS conceptualised and designed the study. MK carried out the initial analyses. HY designed the data collection instruments, and coordinated and supervised data collection. HI performed statistical analysis. MK and YA drafted the initial manuscript and revised the manuscript. MK, HY $\mathrm{HI}, \mathrm{YA}$ and TS approved the final manuscript as submitted.

Funding This work was supported in part by Grants-in-Aid for General Scientific Research, Nos. 24659511 (MK), 23390389 (YA) and 'High-Tech Research Center' Project for Private Universities: matching fund subsidy from the Ministry of Education, Culture, Sports, Science, and Technology, Japan.

Competing interests None.

Patient consent Obtained.

Ethics approval Our study was approved by the Juntendo University Urayasu Hospital Research Ethics Board, and the parents provided informed consent.

Provenance and peer review Not commissioned; externally peer reviewed.

Data sharing statement No additional data are available.

Open Access This is an Open Access article distributed in accordance with the Creative Commons Attribution Non Commercial (CC BY-NC 4.0) license, which permits others to distribute, remix, adapt, build upon this work noncommercially, and license their derivative works on different terms, provided the original work is properly cited and the use is non-commercial. See: http:// creativecommons.org/licenses/by-nc/4.0/

\section{REFERENCES}

1. Kaufman J, Charney D. Effects of early stress on brain structure and function: implications for understanding the relationship between child maltreatment and depression. Dev Psychopathol 2001;13:451.

2. Kessler RC, Davis CG, Kendler KS. Childhood adversity and adult psychiatric disorder in the US National Comorbidity Survey. Psychol Med 1997;27:1101-19.

3. Schilling EA, Aseltine RH Jr, Gore S. Adverse childhood experiences and mental health in young adults: a longitudinal survey. BMC Public Heath 2007;7:30.

4. De Kloet ER, Joels M, Holsboer F. Stress and brain: from adaptation to disease. Nat Rev Neurosci 2005;6:463-75.

5. De Bellis MD, Chrousos GP, Dorn LD, et al. Hypothalamic-pituitaryadrenal axis dysregulation in sexually abused girls. J Clin Endocrinol Metab 1994;78:249-55.

6. Weaver ICG. Epigenetic programming by maternal behavior and pharmacological intervention. Nature versus nurture: let's call the whole thing off. Epigenetics 2007;2:22-8.

7. Champagne FA, Curley JP. Epigenetic mechanisms mediating the long-term effects of maternal care on development. Neurosci Biobehav Rev 2009:33:593-600.

8. Liu D, Diorio J, Tannenbaum B, et al. Maternal care, hippocampal glucocorticoid receptors, and hypothalamic-pituitary-adrenal responses to stress. Science 1997;277:1659-62.
9. Weaver ICG, Cervoni N, Champagne FA, et al. Epigenetic programming by maternal behavior. Nat Neurosc 2004;7:847-54.

10. Boyle MP, Brewer JA, Funatsu M, et al. Acquired deficit of forebrain glucocorticoid receptor produces depression-like changes in adrenal axis regulation and behavior. Proc Natl Acad Sci USA 2005;102:473-8.

11. McGowan PO, Sasaki A, D'Alessio AC, et al. Epigenetic regulation of the glucocorticoid receptor in human brain associates with childhood abuse. Nat Neurosci 2009;12:342-8.

12. Oberlander TF, Weinberg J, Papsdorf M, et al. Prenatal exposure to maternal depression, neonatal methylation of human glucocorticoid receptor gene (NR3C1) and infant cortisol stress responses. Epigenetics 2008;3:97-106.

13. Tyrka AR, Price LH, Marsit C, et al. Childhood adversity and epigenetic modulation of the leukocyte glucocorticoid receptor: preliminary findings in healthy adults. PloS ONE 2012;7:e30148.

14. Perroud N, Paoloni-Giacobino A, Prada $P$, et al. Increased methylation of glucocorticoid receptor gene (NR3C1) in adults with a history of childhood maltreatment: a link with the severity and type of trauma. Transl Psychiatry 2011;1:e59.

15. Mulligan CJ, D'Errico NC, Stees J, et al. Methylation changes at NR3C1 in newborns associate with maternal prenatal stress exposure and newborn birth weight. Epigenetics 2012;7:853-7.

16. Bromer C, Marsit CJ, Armstrong DA, et al. Genetic and epigenetic variation of the glucocorticoid receptor (NR3C1) in placenta and infant neurobehavior. Dev Psycobiol 2013;55:673-83.

17. Hack M, Flannery DJ, Schluchter M, et al. Outcomes in young adulthood for very-low-birth-weight infants. N Engl J Med 2002;346:149-57.

18. Marlow N. Neurocognitive outcome after very preterm birth. Arch Dis Child Fetal Neonatal Ed 2004;89:F224-228.

19. Aylward GP. Cognitive and neuropsychological outcomes: more than IQ scores. Ment Retard Dev Disabil Res Rev 2002;8:234-40.

20. Larroque B, Ancel PY, Marret S, et al.; EPIPAGE Study Group. Neurodevelopmental disabilities and special care of 5-year-old children born before 33 weeks of gestation (the EPIPAGE study): a longitudinal cohort study. Lancet 2008;371:813-20.

21. Hack M. Adult outcomes of preterm children. J Dev Behav Pediatr 2009;30:460-70.

22. Marques AH, Silverman MN, Sternberg EM. Glucocorticoid dysregulation and their clinical correlates. From receptors to therapeutics. Ann NY Acad Sci 2009;1179:1-18.

23. Stark JL, Avitsur R, Padgett DA, et al. Social stress induces glucocorticoid resistance in macrophages. Am J Physiol 2001;280:1799-805.

24. Silverman MN, Sternberg EM. Glucocorticoid regulation of inflammation and its functional correlates: from HPA axis to glucocorticoid receptor dysfunction. Ann NY Acad Sci 2012;1261:55-63.

25. Cole SW. Social regulation of leukocyte homeostasis: The role of glucocorticoid sensitivity. Brain Behav Immun 2008;22:1049-55.

26. Miller GE, Cohen S, Ritchey AK. Chronic psychological stress and the regulation of pro-inflammatory cytokines: A glucocorticoidresistance model. Health Psychol 2002;21:531-41.

27. Miller GE, Chen E, Sze J, et al. A functional genomic fingerprint of chronic stress in humans: blunted glucocorticoid and increased NF-kappaB signaling. Biol Psychiatry 2008;64:266-72.

28. Watterberg KL, Scott SM. Evidence of early adrenal insufficiency in babies who develop bronchopulmonary dysplasia. Pediatrics 1995;95:120-5.

29. Watterberg KL, Gerdes JS, Cole $\mathrm{CH}$, et al. Prophylaxis of early adrenal insufficiency to prevent bronchopulmonary dysplasia: a multicenter trial. Pediatrics 2004;114:1649-57.

30. Ng PC, Lam CW, Fok TF, et al. Refractory hypotension in preterm infants with adrenocortical insufficiency. Arch Dis Child Fetal Neonatal Ed 2001;84:F122-4.

31. Arnold JD, Bonacruz G, Leslie Gl, et al. Antenatal glucocorticoids modulate the amplitude of pulsatile cortisol secretion in premature neonates. Pediatr Res 1998;44:876-81.

32. Yoder B, Martin H, McCurnin DC, et al. Impaired urinary cortisol excretion and early cardiopulmonary dysfunction in immature baboon. Pediatr Res 2002;51:426-32.

33. Masumoto K, Kusuda $\mathrm{S}$, Aoyagi $\mathrm{H}$, et al. Comparison of serum cortisol concentrations in preterm infants with or without late-onset circulatory collapse due to adrenal insufficiency of prematurity. Pediatr Res 2008;63:686-90

34. Nakanishi H, Yamanaka S, Koriyama T, et al. Clinical characterization and long-term prognosis of neurological development in preterm infants with late-onset-circulatory collapse $J$ perinatol 2010;30:751-6.

35. Jobe $\mathrm{AH}$, Bancalari E. Bronchopulmonary dysplasia. Am J Respir Crit Care Med 2001;163:1723-9. 
36. Leakey $\mathrm{TI}$, Zielinski J, Siegfried RN, et al. A simple algorithm for quantifying DNA methylation levels on multiple independent CpG sites in bisulfite genomic sequencing electropherograms. Nucleic Acids Res 2008;36:e64.

37. Cameron AC, Windmeijer FAG. An R-squared measured of goodness of fit for some common nonlinear regression models. Journal of Econometrics 1997;77:329-42.

38. Lutz PE, Turecki G. DNA methylation and childhood maltreatment: from animal models to human studies. Neuroscience 2014;264:142-56.

39. Godfrey KM, Lillycrop KA, Burdge GC, et al. Epigenetic mechanisms and the mismatch concept of the developmental origins of health and disease. Pediatric Research 2007;61:5R-10R

40. Einstein F, Thompson RF, Bhagat TD, et al. Cytosine methylation dysregulation in neonates following intrauterine growth restriction. PLOS ONE 2010;5:e8887.
41. Weaver ICG, D'Alessio AC, Brown SE, et al. The transcription factor nerve growth factor-inducible protein A mediates epigenetic programming: altering epigenetic marks by immediate-early genes. $J$ Neurosci 2007;27:1756-68.

42. Cullen EM, Brazil JC, O'Connor CM. Mature human neutrophils constitutively express the transcription factor EGR-1. Mol Immunol 2010;47:1701-9.

43. Seiler MP, Mathew R, Liszewski MK, et al. Elevated and sustained expression of the transcription factors Egr1 and Egr2 controls NKT lineage differentiation in response to TCR signaling. Nature Immnol 2012;13:264-71.

44. Cohen S, Janicki-Deverts D, Doyle WJ, et al. Chronic stress, glucocorticoid receptor resistance, inflammation, and disease risk. Proc Natl Acad Sci USA

2012;109:5995-9. 